\title{
Práticas educativas e culturais de estudantes e suas percepções sobre as tecnologias móveis na escola
}

\author{
Monica Fantin* \\ Elisa Maria Quartiero**
}

\section{Resumo}

Inserido em uma pesquisa interinstitucional desenvolvida em diferentes contextos socioculturais sobre o Projeto Um Computador por Aluno (UCA), este artigo apresenta um recorte sobre o foco das práticas pedagógicas com objetivo de refletir sobre as práticas educativas e culturais de estudantes e suas percepçóes sobre o Projeto. Com abordagem teórico-metodológica fundamentada na pesquisa mídia-educativa, discute-se um estudo de caso múltiplo realizado em quatro escolas públicas e que envolveu observaçôes do cotidiano escolar, pesquisa-formação, intervenção didática e grupos focais com estudantes de diferentes turmas do ensino fundamental. Para contextualizar a discussão, o texto inicia com um levantamento sobre diferentes pesquisas que tiveram como objeto o Projeto UCA e que foram desenvolvidas entre 2011 e 2014. Em seguida, apresenta-se a escolha metodológica da pesquisa e a discussão sobre as especificidades das práticas culturais e das percepçôes de estudantes a respeito do Projeto. Por fim, o artigo traz algumas consideraçóes que demonstram que a riqueza e a diversidade das práticas presentes em um mesmo projeto também podem ser entendidas como uma polifonia de vozes de estudantes, professores e pesquisadores, como interpretaçóes possíveis que configuram a referida pesquisa em um espaço de alteridade e de imersão na cultura digital.

Palavras-chave: Projeto UCA. Cultura escolar. Inclusão Digital.

* Doutora em Educação pela Universidade Federal de Santa Catarina (UFSC). Professora do Centro de Educação e da Pós-Graduação em Educaçáo da Universidade Federal de Santa Catarina (UFSC).

** Doutora em Mídia e Conhecimento pela Universidade Federal de Santa Catarina (UFSC). Professora aposentada da Universidade do Estado de Santa Catarina (UDESC). 


\section{Introdução}

Este artigo discute os resultados de uma pesquisa sobre o Projeto Um Computador por Aluno ${ }^{1}$ (UCA) que teve como objetivo investigar os desafios e as estratégias que possibilitam a consolidação de uma política pública de inserção de laptops nas escolas, no caso, 21 escolas públicas de Ensino Fundamental nos estados de Santa Catarina e da Bahia, que participaram do referido Projeto. Analisam-se as açóes postas em prática pelos professores e gestores das Escolas para a promoção de processos de formação, gestão e incorporação dos laptops na prática pedagógica.

A pesquisa teve três focos: a) a articulaçáo entre os gestores do Programa; b) as práticas pedagógicas instauradas nas Escolas a partir da inserção dos laptops (estudo de caso em quatro escolas, sendo duas em Santa Catarina e duas na Bahia); c) apoio à criação de uma Rede Colaborativa de Aprendizagem entre os participantes das Escolas do estudo de caso. Entre estes enfoques da pesquisa, o recorte escolhido para discutir neste artigo diz respeito a uma síntese sobre as práticas educativas e culturais de estudantes mediadas com o uso de laptops, dentro do segundo foco de análise. Para tal, contextualizamos o objeto da pesquisa a partir de uma revisão de estudos desenvolvidos a respeito, situamos as escolhas metodológicas desta investigação e apresentamos algumas consideraçôes sobre práticas e percepçóes dos estudantes relacionadas ao recorte escolhido.

\section{O Projeto Um Computador por Aluno como objeto de pesquisa $^{2}$}

A proposta do governo federal de distribuir laptops na modalidade 1:1 envolve três momentos distintos: em um primeiro, denominado pré-piloto, cinco Escolas receberam os laptops (2007); no segundo momento, denominado Piloto - Projeto UCA -, foram distribuídos laptops para um número em torno de 400 Escolas (2009); no terceiro, foi criado, por decreto presidencial, o Programa UCA/PROUCA (2010), responsável pela articulação de financiamento para a compra de laptops por Prefeituras ou Estados interessados através do Banco Nacional de Desenvolvimento Econômico e Social (BNDES). A pesquisa em tela remete-se ao segundo momento da política quando houve a distribuição de laptops para um número maior de Escolas, distribuídas para todos os Estados, com prioridade para Escolas com o Índice de Desenvolvimento da Educação Básica (IDEB) baixo e até 500 estudantes.

Nesta seção, apresenta-se uma síntese de algumas pesquisas desenvolvidas sobre o Projeto UCA, no período de 2011 a 2014. Num corpus de análise constituído por 
cerca de 14 teses e 59 dissertaçóes, foram priorizadas as pesquisas com os seguintes focos: a política pública, os usos dos laptops pelos estudantes, a formaçấo continuada oferecida aos professores das Escolas que receberam os equipamentos, as possibilidades técnicas do laptop, a gestão dos processos de inserção e uso das máquinas no espaço escolar, possibilidades e limites de inclusão digital e social de professores e alunos, entre outras temáticas. É importante destacar que esse levantamento foi realizado no banco de teses da CAPES, em Programas de Pós-Graduação em Educação, com linhas dentro dessas temáticas, e em periódicos indexados. Percebe-se que nem sempre os resumos dos trabalhos contemplam a metodologia da pesquisa desenvolvida, nem anunciam os resultados, o que por vezes dificulta a visão mais contextualizada da pesquisa desenvolvida.

A relação entre "ensino de" e o Projeto UCA foi encontrada em quatro pesquisas cujas especificidades das temáticas - ligadas às diferentes áreas de conhecimento aparecem em diversas outras investigaçôes sobre o tema.

Ao analisar o Projeto UCA a partir do trabalho com professores do ensino de Geografia, Xavier (2011) lista os fatores que considera determinantes para o sucesso do Projeto: a) diálogo entre formação docente e realidade escolar; b) formação docente visando o uso pedagógico dos recursos tecnológicos e sua respectiva elucidaçáo como fenômeno histórico-social; c) abordagem pedagógica dos usos das tecnologias e suas relaçôes com os campos específicos do saber; d) infraestrutura compatível com as especificidades do público-alvo (número de equipamentos, capacidade de rede, durabilidade da bateria); e) capacitação constante a partir da união entre especialistas em informáticas, pedagogos e professores específicos de cada disciplina, como condição para trazer para dentro da função docente a responsabilidade principal da formação; f) revisão da regulamentação da carreira docente (carga-horária, condiçôes salariais). Considera-se importante iniciar a discussão com esses fatores, pois eles, em maior ou menor grau, farão parte e serão objeto de discussão em quase todas as pesquisas analisadas. Ainda em 2011, Xavier apontou os principais desafios para a consolidação de uma política pública para a educaçáo no contexto do Projeto UCA e a partir daí vamos encontrar tais aspectos em diferentes pesquisas que procuram adensar o conhecimento na área.

No estudo sobre como docentes de Língua Portuguesa do município de Tiradentes, MG, inserem os laptops nas suas práticas escolares, Teixeira (2012) utiliza como base teórica para a sua tese o Paradigma da Complexidade. Com enfoque sistêmico de observação do contexto, a pesquisa enfatiza a interação dos agentes e o Modelo de Difusão Tecnológica de Rogers (2003), como indicador da difusão da tecnologia. Suas conclusóes apontam o fortalecimento do uso das tecnologias no município a partir da inserção dos laptops nas Escolas. 
Com base em referencial piagetiano, Rigoni (2012) realizou pesquisa com um grupo de estudantes de 13 anos, do $7^{\circ}$ ano do Ensino Fundamental, em uma escola pública municipal participante do Projeto UCA no Rio Grande do Sul. Seu objetivo foi compreender os mecanismos sociocognitivos presentes nas trocas interindividuais dos estudantes nos diferentes contextos de aprendizagem em que faziam uso do laptop educacional na disciplina de História. A autora evidencia que a mobilidade do laptopmodelo 1:1 - pode configurar novas relaçóes e desafios ao processo de ensino e aprendizagem. Com relação aos mecanismos sociocognitivos, a dissertaçáo evidencia uma tendência a relaçôes de conformismo e de coação nas trocas interindividuais entre os estudantes e um falso equilíbrio de cooperação.

Nesta mesma linha de investigação, sob outro aporte teórico e área de conhecimento, Souza (2013) pesquisou as interaçóes desencadeadas entre estudantes de uma turma do $9^{\circ}$ ano do Ensino Fundamental de uma escola municipal da cidade de Belo Horizonte, MG, a partir do uso do laptop educacional do Projeto UCA para trabalhar conteúdos de Matemática. Segundo o autor, foi possível constatar que o uso do laptop em sala de aula proporcionou a criação de um ambiente fértil para a promoção da aprendizagem de Matemática. Em sua dissertação, o autor relata que em algumas oportunidades os estudantes interagiram com seus pares durante as atividades com o laptop e os diálogos "enriqueceram o ambiente de aprendizagem matemática" (SOUZA, 2013, p. 6).

Em artigo com os resultados de pesquisa de mestrado, Silva e Susin (2012) analisam a pesquisa intervenção realizada na disciplina de Ciências junto a duas turmas de $7^{0}$ ano do Colégio de Aplicação da Universidade Federal do Rio Grande Sul (UFRGS), em Porto Alegre, com a participação de um professor e 60 estudantes. As autoras vivenciaram o cotidiano escolar e coletaram dados sobre a utilização dos laptops educacionais no processo de ensino e de aprendizagem de conhecimentos científicos. A análise teve seu foco nas "propostas de atividades didáticas subsidiadas por um ambiente virtual e nas práticas discursivas dos estudantes frente ao uso da tecnologia" (SILVA; SUZIN, 2012, p. 4), e apontam a "importância da interatividade e da colaboração entre professor e aluno durante a realização das atividades com computadores, de modo que os princípios pedagógicos não permaneçam em uma lógica unidirecional de transmissão do conhecimento" (SILVA; SUZIN, 2012, p. 14). As autoras concluem que "não basta aderir a propostas de atividades ditas virtuais para conquistar o envolvimento dos estudantes da era digital", e que são necessárias "articulaçóes teórico-práticas entre os conteúdos trabalhados e os objetivos das atividades realizadas com os recursos informáticos" (SILVA; SUZIN, 2012, p. 16).

Embora os problemas e limites técnicos e operacionais do equipamento e das questóes infraestruturais, como o acesso às redes e falta de manutenção, apareçam em 
grande parte das pesquisas desenvolvidas sobre o Projeto UCA, os problemas e soluçóes do Sistema Operacional Metasys presente nos laptops foram analisados por Pinto (2012) na sua dissertação, que teve como campo empírico o Colégio de Aplicação da Universidade Federal de Sergipe (UFS). O autor aponta para a necessidade de formação para que os professores possam entender o Sistema Operacional dos laptops e assim utilizarem melhor os equipamentos e aposta na elaboraçáo de um tutorial como meio de ajuda para a resolução dos problemas apresentados pelo Sistema Operacional Metasys.

$\mathrm{Na}$ especificidade de duas escolas municipais no estado de Pernambuco, Silva (2012) desenvolveu uma pesquisa junto a professores e em sua dissertação concluiu que a implementação do Projeto UCA nessas Escolas não trouxe contribuiçôes significativas para instigar a reflexão do professor e permitir a inclusão digital dos professores e estudantes. Segundo a autora, isso se deve, em parte, às lacunas apresentadas pelo Projeto (falta de formaçáo técnica dos professores, falta de suporte técnico e pedagógico, bem como o mau funcionamento dos equipamentos).

Os documentos oficiais do Programa UCA foram analisados no doutorado de Sarian (2012), que discutiu as tramas discursivas presentes nos documentos reguladores visando estabilizar e desestabilizar os sentidos da discursividade institucional sobre os quais o Programa se edifica como uma política pública no contexto maior da sociedade e da educação brasileira.

Investigar a experiência do UCA Total na cidade Tiradentes, MG, na qual todas as escolas da rede municipal receberam os laptops do Projeto, foi objetivo da pesquisa de Schneider (2012). Ela analisou as possíveis mudanças que ocorrem nas dimensóes cognitivas e sociais de pessoas com deficiência quando mediadas por laptops em contexto escolar, e identificou movimentos inclusivos desencadeados a partir da implementaçáo do Projeto, tanto nas dinâmicas de sala de aula e nas escolas quanto na gestáo educacional do município. A dissertaçáo concluiu que os problemas de inclusão de estudantes com deficiências extrapolam a discussão sobre a inserção de tecnologias na escola, pois anteriormente ao Projeto o município tinha propostas muito tímidas para a inclusão e os equipamentos não mudaram muito este quadro.

As possibilidades pedagógicas da Educação Física escolar dentro dos Projetos UCA, no Brasil, e do Plan CEIBAL, no Uruguai, foram analisadas na dissertação de Piovani (2012). Para isso, o estudo realizou três experiências de uso do computador por estudantes de turmas do $5^{\circ}$ e $6^{\circ}$ ano de uma escola municipal da cidade de Brusque, em Santa Catarina, Brasil, e duas escolas de Ensino Primário na cidade de Montevidéu, no Uruguai. A investigação demonstrou a relevância do uso de técnicas e princípios da pedagogia Freinet, relacionados e acrescentados aos conceitos de mídia-educação e 
media literacy, para os professores de Educação Física utilizarem as tecnologias nas suas propostas de ensino.

Os modos de interação construídos e praticados por professores e estudantes atuantes no Projeto UCA em escolas do Distrito Federal foram analisados na dissertação de Faria (2012). O tensionamento existente entre os termos interação e interatividade lhe conduziu à elaboração de uma tipologia própria, na qual os termos Interaçáo Estática e Interação Dinâmica classificam os modos de interação encontrados e verificados a partir de observaçóes das aulas e as entrevistas realizadas com estudantes e professores.

Ao analisar a construção do pensamento crítico entre estudantes que realizam pesquisa escolar na web com os laptops, Valle (2011), em sua dissertação, identifica os critérios utilizados pelos alunos na seleção da informação e as habilidades para a análise crítica das informaçóes encontradas. A partir de observaçóes em sala de aula, do comportamento dos estudantes ao utilizarem os laptops em suas práticas de pesquisa, e da realização de entrevistas clínicas com descrição do pensamento do próprio aluno, a autora evidencia os indícios de construção de pensamento crítico viabilizado pelas habilidades cognitivas mobilizadas no uso dos equipamentos em suas atividades de pesquisa.

Investigar os impactos do Projeto UCA em uma escola do município de Sáo João da Ponta, no Pará, foi objetivo da dissertação de França (2014). Seus resultados, corroborando com muitos outros, indicam que as pesquisas na Internet são as principais atividades desenvolvidas pelos professores. Os estudantes entrevistados afirmam que utilizam o laptop muito mais para entretenimento do que para realizar atividades escolares. A autora ressalta a importância do projeto para a localidade e afirma que representa um ganho nos aspectos de inclusão digital e social, especialmente pela distribuiçáo dos laptops, o que permitiu, segundo ela, não apenas a familiarização do aluno com o equipamento, mas também de toda a sua família, pois esta tecnologia era desconhecida para a maioria das pessoas no município.

Entre investigaçóes correlatas à pesquisa que originou este artigo, destacam-se cinco dissertaçôes: Silva (2014) desenvolveu pesquisa em que procura ressignificar o sentido de inclusão digital e o uso das Tecnologias da Informação e Comunicação (TICs) em uma escola do município de Salvador e de Candeias na Bahia a partir do Projeto UCA; Zanata (2013) discute as mudanças na gestáo escolar e as possíveis inovaçóes educacionais com os usos das tecnologias móveis em 10 Escolas participantes do Projeto UCA em Santa Catarina; Miranda (2013) discute as multissensorialidades e aprendizagens possibilitadas pelo uso das tecnologias móveis entre crianças de uma escola municipal de Florianópolis, SC; Kretzer (2013) analisa as práticas educativas dos 
professores no processo de incorporação das tecnologias digitais no cotidiano escolar de uma escola municipal de Florianópolis, SC; Neira (2014) analisa as possibilidades da rede como espaço de encontro e ressignificação do trabalho colaborativo entre os professores de uma escola municipal em Florianópolis, SC. Dentro das pesquisas realizadas, destacam-se ainda duas teses: a de Cordeiro (2014), que analisa as tecnologias digitais móveis no cotidiano de Escolas participantes do Projeto UCA no estado da Bahia; e a de Araujo (2014), com uma investigação sobre o sentido da autoria do professor na cibercultura e as redes da criaçáo no cotidiano de uma escola de Itabuna, BA.

Com esse recorte sobre o material pesquisado, busca-se evidenciar as diferentes escolhas teórico-metodológicas e os resultados advindos das pesquisas acadêmicas desenvolvidas sobre o Projeto UCA que, mesmo sem aprofundar a reflexão e as ênfases de análises neste momento, parecem referendar a fugacidade das políticas e a inércia das práticas, como destacam Sancho e Alonso (2012), e com isso demonstram que a inserçáo de tecnologias nas escolas não é suficiente para transformar as práticas (QUARTIERO, BONILLA, FANTIN, 2012). No entanto, podemos afirmar que a inserção de laptops nas escolas públicas gerou um grande movimento entre muitos outros pesquisadores interessados em entender o alcance e os desdobramentos desta política pública que discute educação, tecnologia e cultura digital, como podemos constatar na publicação de Sampaio e Elia (2012), que congrega 27 diferentes pesquisas desenvolvidas com a finalidade de avaliar a proposta do Projeto UCA.

Diante desse breve levantamento de pesquisas sobre o Projeto UCA, destaca-se a especificidade teórico-metodológica da pesquisa interinstitucional desenvolvida em dois estados brasileiros - Santa Catarina e Bahia - dentro da singularidade das questóes sobre as práticas pedagógicas desenvolvidas por professores e estudantes a partir da participação no Projeto UCA.

\section{Práticas educativas e percepções de estudantes no contexto do Projeto UCA em Santa Catarina e na Bahia}

\section{Escolhas teórico-metodológicas}

Em um percurso teórico-metodológico fundamentado nos pressupostos da pesquisa mídia-educativa (RIVOLTELLA, 2005, 2013; TUFTE; CHRISTENSEN, 2009; BUCKINGHAM, 2008), a investigação envolveu estudo de caso múltiplo realizado em quatro Escolas das 21 participantes da pesquisa em dois estados brasileiros, Bahia e Santa Catarina, revelando diversas faces da diversidade do Nordeste e do Sul do país. Esta escolha possibilitou acompanhar e analisar as práticas pedagógicas que foram 
instauradas a partir da inserção das tecnologias móveis nas Escolas, identificar as representaçóes e os usos do laptop entre estudantes e professores, e discutir as possibilidades de contribuir com o desenvolvimento de processos inovadores no meio escolar por meio da pesquisa-formação.

A fim de verificar a adequação do laptop entre as diferentes faixas de idade dos estudantes, selecionou-se turmas do $2^{\circ}$ ao $9^{\circ}$ ano e seus respectivos professores. Com isso, foi possível ter uma ideia geral do uso do laptop por parte de crianças menores, préadolescentes, adolescentes e seus professores, bem como aprofundar aspectos relacionados às atividades que desenvolvem em contexto formal e informal, opiniōes, expectativas, problemas, dificuldades e desafios. Outro aspecto importante na pesquisa junto às Escolas foi analisar em que medida as aprendizagens com o uso do laptop favorecem a perspectiva da multiliteracies.

No estado de Santa Catarina, integraram o estudo de caso uma Escola Básica Municipal, situada em Florianópolis, na zona urbana, com 335 estudantes e 20 professores, e outra Escola Básica Municipal, situada em Jaraguá do Sul, também em zona urbana, com 643 estudantes e 28 professores. No estado da Bahia, integraram o estudo uma Escola Básica Estadual, situada em Itabuna, na zona urbana, com 400 estudantes e 16 professores, e uma Escola Básica Municipal, situada em Irecê, na zona urbana, com 450 estudantes e 19 professores.

A definição das Escolas para o estudo de caso ficou centrada no aceite prévio da instituição, o que foi oficializado em virtude de haver uma relação estabelecida previamente em função de outras pesquisas e formaçôes realizadas nesses espaços escolares. Durante o ano de 2012, equipes de pesquisadores estabeleceram cronogramas de visitas às escolas - semanais em SC e mensais na BA - que tiveram o objetivo de acompanhar as atividades didáticas realizadas com os laptops, em turmas definidas a partir de negociaçóes com os próprios professores. Por demanda das Escolas, também foram desenvolvidos diferentes projetos de formação durante o período de permanência dos pesquisadores para a coleta de dados, na perspectiva da pesquisaformação (DURAND; SAURY; VEIRUNES, 2005; LONGAREZI; SILVA, 2008; QUARTIERO; FANTIN, 2014). A coleta de dados envolveu observaçóes em sala de aula, entrevistas com professores e grupos focais com estudantes.

O quadro 1, a seguir, apresenta as turmas e os professores participantes da pesquisa em cada Escola. 


\section{Quadro 1 - Turmas e professores envolvidos no estudo de caso da pesquisa}

\begin{tabular}{|c|c|c|}
\hline Escolas & Turmas & Professores envolvidos \\
\hline EBM AISC & $2^{\circ}, 4^{\circ}, 6^{\circ}$ e $9^{\circ}$ ano & $\begin{array}{l}06 \text { (02 dos Anos Iniciais, 01de Educaçáo Física, } 01 \text { de } \\
\text { Ciências e } 02 \text { de Língua Portuguesa) }\end{array}$ \\
\hline $\mathrm{EBM} \mathrm{B} \backslash \mathrm{SC}$ & $3^{\circ}, 6^{\circ}$ e $9^{\circ}$ ano & 09 (02 dos Anos Iniciais e demais professores do 6 e $9^{\circ}$ ano 07$)$ \\
\hline EBE A\BA & $\begin{array}{c}5^{\circ}, 6^{\circ}, 7^{\circ}, 8^{\circ} \text { e } 9^{\circ} \\
\text { ano }\end{array}$ & $\begin{array}{c}03 \text { (01 de História, Geografia e Artes, } 01 \text { de Redaçáo e } \\
01 \text { de Língua Inglesa e Artes - todos atuam nas turmas } \\
\text { observadas) }\end{array}$ \\
\hline $\mathrm{EBM} B \backslash \mathrm{BA}$ & $2^{\circ}$ e $5^{\circ}$ ano & 02 (Anos Iniciais) \\
\hline
\end{tabular}

Fonte: Produção dos pesquisadores da pesquisa (QUARTIERO; FANTIN, BONILLA, 2014).

Para investigar as práticas pedagógicas nessas Escolas e, mais especificamente, nessas turmas de estudantes, foi construída uma matriz para observação e análise das competências/habilidades com o uso das tecnologias móveis que se esperava encontrar, a partir das indicaçôes presentes na literatura da área de pesquisa e que orientaram e serviram de balizamento para a observação das práticas nas Escolas (JENKINS, 2006; WARSCHAUER, 2006; LANKSHEAR; KNOBEL, 2007; UNESCO, 2008; ALONSO, 2011), sendo elas a cultura digital, alfabetização digital, múltiplas linguagens, capacidade lógica, colaboração, criatividade, compartilhamento e autoria, todas analisadas em uma tripla dimensão: a atividade desenvolvida, a ação do professor e o trabalho dos estudantes, observando as atitudes em sala de aula, as interaçóes e mediaçốes que realizavam.

Os grupos focais com os estudantes ocorreram ao longo do ano letivo de $2012 \mathrm{e}$ tiveram como objetivo central entender as expectativas e representaçóes dos estudantes sobre o laptop, assim como os usos que faziam no cotidiano da Escola e noutros espaços fora dela. $\mathrm{O}$ quadro 2 permite visualizar o número de estudantes envolvidos nesses grupos por Escola pesquisada.

\section{Quadro 2 - Grupos focais de estudantes das Escolas do estudo de caso}

\begin{tabular}{|c|c|c|l|c|}
\hline Escolas & No degrupos $^{\text {Participantes }}$ & \multicolumn{1}{|c|}{ Turmas } & $\begin{array}{c}\text { Total de estudantes nas } \\
\text { turmas }\end{array}$ \\
\hline EBE A \BA & 02 & 13 & $5^{\circ}, 6^{\circ}, 7^{\circ}, 8^{\circ}$ e $9^{\circ}$ ano & 113 \\
\hline EBM B \BA & 02 & 16 & $2^{\circ}$ e $5^{\circ}$ ano & 60 \\
\hline EMEF B।SC & 05 & 35 & $3^{\circ}, 4^{\circ}, 5^{\circ}, 8^{\circ}$ ano & 75 \\
\hline EBM A ISC & 04 & 26 & $4^{\circ}, 5^{\circ}, 8^{\circ}$ e $9^{\circ}$ ano & 85 \\
\hline Total & $\mathbf{1 3}$ & $\mathbf{9 0}(\mathbf{2 7 , 0 2} \%)$ & $\mathbf{1 5}$ & $\mathbf{3 3 3}$ \\
\hline
\end{tabular}

Fonte: Produção dos pesquisadores da pesquisa (QUARTIERO; FANTIN, BONILLA, 2014). 
As entrevistas realizadas com seus professores sobre as possibilidades de inovaçóes pedagógicas a partir dos usos das tecnologias móveis subsidiaram as propostas de formaçáo desenvolvidas no decorrer da pesquisa. Aliado a isso, em algumas turmas houve intervenção didática com o desenvolvimento de propostas de atividades com o uso das tecnologias móveis na perspectiva da mídia-educação, a fim de aprofundar certos aspectos das categorias observadas.

A combinaçáo de tais instrumentos e estratégias permitiu ampliar o olhar às diferentes realidades e assegurar o diálogo entre os sujeitos da pesquisa, na busca de outros tipos de interação entre "pesquisadores e pesquisados" e na construção de outros vínculos no processo de investigaçáo. $\mathrm{O}$ cruzamento dos dados obtidos com os diferentes instrumentos e suas análises se pautaram tanto nas pré-categorias elencadas quanto em outras que emergiram durante o processo.

\section{Aproximaçóes e práticas culturais de estudantes com tecnologias móveis}

As práticas educativas e culturais dos estudantes com o uso do laptop e suas possíveis aprendizagens na escola e fora dela se constroem a partir de percepçóes, motivaçóes, múltiplas linguagens e diferentes formas de envolvimento e participação na cultura digital.

Um ponto de partida para entender as relaçóes dos estudantes com o artefato na escola é considerar que estes se constroem em espaços mediados por diversos fatores que compóem um ecossistema comunicativo (MÁRTIN-BARBERO; REY, 2004) de todo o entorno educativo. $\mathrm{O}$ contexto sociocultural dos estudantes e professores, os diversos ambientes da Escola - que configuram uma determinada arquitetura escolar -, a formação do professor e as propostas de mediação para o uso do laptop vão configurar as práticas midiáticas e culturais dos estudantes. Nesse sentido, as relaçôes e as práticas dos estudantes com as atividades de aprendizagem com o laptop no espaço da escola ocorrem a partir de diálogos que transitam por percepçôes, motivaçôes, múltiplas linguagens, diferentes envolvimentos e formas de participação.

Constata-se que certas posturas e atitudes se repetem independentemente dos contextos socioeconômicos e culturais, transcendendo fronteiras entre Bahia e Santa Catarina. Por vezes, as práticas se diferenciam mais em uma mesma Escola - que supostamente teria as mesmas condiçôes infraestruturais de máquina e acesso à rede, as mesmas condiçóes de trabalho e formação do professor, que lidaria com o mesmo perfil de estudantes e que teoricamente partiriam de mesmas propostas curriculares - e não tanto em funçáo dos diferentes contextos. Como por exemplo, os problemas com o laptop, as motivaçóes, os usos na pesquisa e as preferências por jogos e redes sociais. Nesse caso, mesmo considerando os "sujeitos historicamente situados", parece que em 
algumas situaçôes determinadas atitudes e posturas se referem a certo ethos de ser criança, adolescente, aluno, professor, e do fato de que "escola é escola em qualquer lugar"!

Por outro lado, as significativas diferenças e desigualdades em relação ao acesso à tecnologia, aos níveis de competência necessários para o uso do laptop, bem como a maior ou menor imersão na cultura digital evidenciaram diferentes apropriaçóes. Em alguns casos, os fatores econômico e cultural fizeram diferença, por exemplo, em negociaçóes sobre o acesso à rede na escola, visto que este aspecto era assegurado tanto pela condição socioeconômica familiar como por uma participação mais atuante na escola. Em consequência, o capital cultural familiar também repercutia nas mediaçôes e nos acompanhamentos diferenciados sobre as atividades de crianças e adolescentes em rede fora da escola.

Outros aspectos em que se observou as desigualdades em relação ao acesso às tecnologias, diz respeito ao próprio uso do laptop - como revela o depoimento de um estudante de um contexto desfavorecido: "a primeira vez que eu peguei ele [o laptop] náo sabia mexer em nada, não sabia onde era a internet, não sabia colocar a internet e depois eu mexia em tudo" -, à apropriação dos conteúdos midiáticos, em que a prioridade na dimensão do consumo de informaçóes em detrimento à produção de conteúdos estava muito mais presente. $\mathrm{O}$ dado da inclusão digital faz diferença, pois se os estudantes não têm acesso à rede em casa, é na escola que terão a oportunidade de participar dessa cultura de forma crítica e construir suas competências, seus fazeres e seus saberes.

Assim, crianças e adolescentes que têm acesso à tecnologia em casa, usam-na para jogar, navegar na internet e em sites de relacionamento, trocar mensagens instantâneas e outras atividades que pouco se parecem com as solicitadas pela aprendizagem escolar. Por sua vez, o que a escola solicita aos estudantes em relação aos usos do laptop ainda é muito limitado e "escolarizado", o que só aumenta e distância entre as aprendizagens formais e informais, ou seja, a cultura do tempo livre e convergência das mídias de um lado, e a cultura escolar dos "documentos escritos", na falta de um termo mais adequado. Dessa forma, a questão que se evidencia é como estabelecer o diálogo entre essas culturas tão diferentes? E como superar o abismo entre os que têm acesso "de qualidade" à cultura digital e todas suas possibilidades e aqueles que têm o acesso "pobre" via equipamentos e conexáo de baixa qualidade?

Nesse aspecto, verifica-se a enorme dificuldade da escola minimizar esta distância, ainda mais quando as propostas didáticas de uso das tecnologias digitais são organizadas e desenvolvidas dentro de uma lógica do consumo e não da produção, evidenciado entre os usos de muitos estudantes. Desse modo, atividades como pesquisa na internet, apresentação de slides, produção textual, história em quadrinho, produção 
de audiovisual, criação de blogs, pouco dialogam com as práticas midiáticas desenvolvidas fora da escola, como assistir a videoclips e outros vídeos, baixar músicas, compartilhar imagens e vídeos, enviar e receber mensagens, interagir nas redes sociais. Tal distanciamento dificulta as possibilidades de mediaçóes mais críticas sobre os repertórios e as práticas de consumo midiático.

Entre as apropriaçôes diferenciadas da cultura digital na escola, observou-se maior entusiasmo no uso do laptop entre estudantes dos Anos Iniciais (entre 6 e 10 anos), tanto em relação às atividades didáticas quanto em relaçáo aos usos das redes. Entre os adolescentes houve um menor envolvimento e interesse devido aos limites técnicos da máquina, as dificuldades de acesso à rede e capacidade de navegação. Em uma das Escolas houve bloqueio do acesso às redes sociais, o que se constituiu em mais um problema para os adolescentes. No entanto, nas escolas em que o acesso à rede não era bloqueado, verificou-se diversas situaçôes em que a atenção distribuída ou mesmo a distração dos estudantes ocorria de diferentes formas e por vezes "competia" com a proposta didática. Esse aspecto foi percebido e problematizado por estudantes e professores e tem sido objeto de diversos estudos (BUCKINGHAM, 2008; GEE; HAYES, 2011; RIVOLTELLA, 2013).

Nesse sentido, constata-se que em alguns contextos os usos e as preferências das crianças menores por jogos se diferenciaram dos interesses dos adolescentes, marcados pelas redes sociais. Com isso, observa-se também que as motivaçóes, as atenções e mesmo as distraçôes ocorriam de formas diversas. Do mesmo modo, os diferentes estilos de aprendizagem dos estudantes fazia com que alguns manifestassem preferências por atividades individuais, outros por atividades coletivas e/ou compartilhadas com laptop, e outros ainda demonstravam suas predileçóes por atividades desenvolvidas no caderno e/ou com uso do laptop e outros suportes, como se pode observar no diálogo desenvolvido em um grupo focal com crianças em torno de 7 anos e que também expressam outros aspectos tratados acima:

E2: Eu também gosto do caderno porque dá para você ver a base inteira e no UCA[laptop] não da para ver não.

E3: Eu prefiro no uquinha porque no uquinha pode pesquisar e fazer muitas coisas e no caderno a gente só escreve.

E7: A pessoa não pode jogar no caderno!

E4: Eu também prefiro no uquinha porque tem várias coisas para vocêver, escrever ejogar. Edispersar a nossa mente!

Ou seja, as crianças demonstram ter noção das diferentes formas de aprendizagens com ou sem o laptop, de suas preferências de uso no contexto da cultura digital e também de suas possíveis implicações em relação à atenção-distração. 
Entre alguns aspectos que sinalizam processos de mudanças em curso nas práticas midiáticas e na cultura mais ampla que atravessam as fronteiras das atividades desenvolvidas na escola e fora dela, destaca-se a necessidade de considerar as aprendizagens formais e informais em diálogo, e não como competências isoladas. É o caso de reconhecer certas práticas como os novos letramentos/new literacies (LANKSHEAR; KNOBEL, 2007, 2013) que potencializam o sentido das atividades colaborativas, do compartilhamento de conteúdos em rede, das atividades de remix, fanfiction e muitas outras que exigem competências e habilidades da cultura participativa (JENKINS, 2006) na perspectiva das multiliteracies. Apesar de fazerem parte do cotidiano de muitos dos estudantes que participaram da pesquisa, ainda não estão presentes nas Escolas nem integradas ao currículo e em seu desdobramento nas atividades didáticas. Essa constatação também foi percebida pelos próprios estudantes ao criticar o pouco uso das tecnologias na escola. Desse modo, os estudantes ressaltam a necessidade de a escola perceber que precisa ser mais coetânea com os contextos culturais atuais, como expressa o depoimento e a sugestão dada por um estudante participante da pesquisa: "indico ao professor usar o face e também trazer outras coisas, ficar ligado no que está acontecendo e trazer como atividade para sala de aula, porque têm outras coisas que nós aprendemos".

Com isso, eles revelam a necessidade de interpretar o mundo fora da escola trazendo seus saberes fortuitos, provindos da cultura midiática e juvenil, para o espaço escolar, minimizando o sentimento de perda de controle quando essa cultura entra na escola, visto que "o novo divisor digital [...] reflete uma disjunção histórica mais ampla entre a cultura do lazer cotidiano dos jovens e a cultura da escola" (BUCKINGHAM, 2008, p. 10).

\section{Percepçóes e representaçóes de estudantes sobre o laptop}

As práticas discutidas acima também se revelam nas falas, percepções e representaçôes dos estudantes sobre o Projeto (QUARTIERO, FANTIN, BONILLA, 2014). Afinal, diferentes imagens, situaçóes e palavras que vem à mente de estudantes podem atuar como um importante dispositivo quando queremos identificar o sentido de certas representaçóes sociais a respeito do laptop. Para Moscovici (2009), as representaçôes sociais constroem-se a partir de experiências diretas ou indiretas e, entre outros fatores, são mediadas pela cultura, comunicação e linguagem, além da subjetividade de cada um.

Desse modo, se palavras, gestos e atitudes traduziram algumas compreensões dos professores e seus modos de ver o laptop na Escola, com os estudantes buscou-se imagens e falas sobre suas práticas. Durante os grupos focais foi solicitado aos 
estudantes que fizessem uma colagem a partir da escolha de imagens de revistas e jornais e associassem o laptop a algo positivo e/ou negativo. Caso náo encontrassem a imagem pretendida, poderiam desenhá-la. Em seguida, deveriam explicitar o motivo das suas escolhas e o sentido da metáfora utilizada.

Apesar da variação das imagens dentro e entre os grupos, segundo especificidades, diferenças socioculturais e o sentido de pertencimento nos diversos contextos da pesquisa, grande parte das significaçóes e explicaçóes se assemelhavam, independentemente dos estudantes e das Escolas. Também foi observado certo contágio entre as ideias dos estudantes durante a atividade, o que certamente contribuiu para algumas opiniōes comuns.

As imagens de símbolos conhecidos e ícones de jogos, internet e redes sociais apareceram em dois sentidos: na positividade para expressar a diversidade de interaçóes que permitem e na negatividade para ilustrar a dificuldade de acesso à rede, a proibição ou o bloqueio das redes. Imagens de relógios expressaram a relação com o tempo, velocidade de acesso às informaçóes e a possibilidade de saber as horas, e também expressaram a lentidão do laptop e da internet nas Escolas. O mesmo aconteceu com a imagem do fone de ouvido, utilizado para enaltecer as possibilidades de ouvir e baixar músicas e para representar problemas de som do laptop.

No sentido afirmativo, internet - jogos - pesquisa foram palavras-chave que apareceram nas colagens e nos desenhos, seguidas das expressóes conversa com amigos, redes sociais e das palavras Facebook, fotografia, música. Algumas palavras como compras, viagens e cultura tiveram presença significativa em apenas uma Escola. É curioso observar que a palavra conhecimento tenha aparecido apenas em duas Escolas, embora a atividade de pesquisa tenha estado presente em todos os contextos investigados.

Os sentidos de negatividade do laptop foram expressos nas expressóes internet lenta, trava, pouca memória e tela pequena transcenderam os contextos. A imagem de uma pessoa de idade andando de bengala com perna quebrada expressava a internet lenta; fios interrompidos e quebrados representavam a falta de acesso à rede; caminhão carregando carro quebrado ilustrava a ideia do computador danificado; mulher com a mão na testa significava a pouca memória do equipamento. Outras imagens curiosas e originais chamaram atenção,assim como a ausência de aspectos negativos para um grupo em uma Escola. Alguns argumentos que apareceram apenas em uma Escola revelam certas singularidades dos contextos investigados: falta de acesso e conexão quebrada em Escola que não teve conexão; redes sociais associadas à falta de atenção dos estudantes expressava a decisão da Escola pelo bloqueio; ponto de interrogação retratava a ausência do laptop devido aos defeitos e à falta de manutenção, evidenciada sobretudo nessa Escola. Tais representaçóes se complementam com as percepçóes explicitamente 
manifestadas pelos estudantes quando solicitados a completar frases sobre as atividades desenvolvidas na Escola com o laptop.

Importante destacar que entre os principais argumentos dos estudantes sobre a importância do laptop na Escola, evidencia-se o sentido de positividade atribuído ao artefato e suas possibilidades de interação social, jogos, internet e aprendizagem. A motivaçáo também aparece como um argumento importante na percepção dos estudantes, que de certa forma também pode ser entendido como reflexo de um dos princípios que consta nos documentos oficiais da ONG One Laptop per Child (OLPC) e do Programa UCA, que por sua vez, também estão presentes nos discursos de professores e familiares e da mídia em geral mediando suas falas e percepçôes.

\section{Algumas considerações}

Ao contextualizar o Projeto UCA na diversidade de pesquisas acadêmicas desenvolvidas nos últimos anos, destacam-se algumas especificidades teóricas e metodológicas de uma pesquisa desenvolvida em diversos contextos sobre o tema. Nessa pesquisa, constatam-se singularidades e padróes que se repetem e evidenciam a riqueza da diversidade presente em um mesmo Projeto traduzido em múltiplas interpretaçôes possíveis sobre diferentes focos de uma pesquisa interinstitucional. Entre falas de estudantes crianças e adolescentes, professores, pesquisadores e tantos estudiosos, construiu-se uma espécie de polifonia sobre as práticas com laptop no contexto da pesquisa.

Em estudos que analisam práticas educativas e culturais no contexto da cultura digital na escola, a questão da formação continuada de professores e estudantes é um fator determinante e que faz diferença nos resultados de pesquisas. Nesta pesquisa, observou-se que o caráter da pesquisa-formação que aconteceu nas Escolas teve aspectos diferenciados e configurou especificidades em relaçáo às atividades desenvolvidas com o laptop. A esse respeito, enfatiza-se a importância da perspectiva de pesquisa-formação para fortalecer a articulaçáo entre os resultados de pesquisa e as práticas de formaçáo continuada docente, buscando superar a oposição entre uma "epistemologia dos saberes" e uma "epistemologia da açáo", que Durand, Saury e Veyrunes (2005, p. 39) enfatizam.

Aliado a isso, destaca-se que, embora a metodologia e os instrumentos de pesquisa tenham sido os mesmos nos diferentes contextos do estudo de caso múltiplo, os estilos dos pesquisadores e suas singularidades na conduçáo das entrevistas e dos grupos focais é um aspecto que merece ser considerado. As falas de estudantes e professores revelam os diferentes modos de os pesquisadores estimularem e/ou 
problematizarem os depoimentos dados, as maneiras de assegurar a palavra a todos ou a escuta privilegiada de alguns. Também revelam os grupos de afinidades, que Gee e Hayes (2011) mencionam, assim como os diferentes tipos de vínculos que se constroem durante a pesquisa. Com isso, houve situaçóes em que se constatou maior elaboração e detalhes nas respostas e falas dos sujeitos por um lado, e certo desestímulo e ausência de diálogo por outro, o que evidencia a singularidade das diferentes conduçóes das entrevistas e dos grupos focais.

Nesse sentido, é importante destacar que a relação entre pesquisador e sujeito de pesquisa é muito peculiar e evidencia diferentes faces de uma relação de parceria que ocorre e que é mediada por diversos fatores. Por vezes se percebe certas armadilhas do fazer pesquisa, em que o sujeito responde aquilo que imagina que o outro quer ouvir ou o que seria considerado mais aceito e socialmente válido em tal situação de pesquisa. É nesse processo que se constrói a coautoria entre pesquisadores e sujeitos de pesquisa e que faz diferença na coleta dos dados e sua posterior análise e interpretação.

Por fim, a constataçáo de singularidades e padrôes que se repetem juntamente com a enorme riqueza e diversidade presente em um Projeto federal de inserção de tecnologias móveis no espaço público escolar pode ser traduzida em diversas interpretaçóes possíveis sobre os diferentes objetos de estudo privilegiados nessa pesquisa interinstitucional.

Foi nessa tessitura das falas, escutas e olhares de estudantes, professores e pesquisadores que se construiu uma polifonia sobre o Projeto UCA. Nessas diferentes vozes e ritmos nem sempre a sintonia das práticas investigativas e formativas deu o tom da pesquisa. Certos descompassos também foram importantes para perceber a escola e a universidade como espaços de alteridade que podem dar visibilidade às nuanças e cores dos diferentes cenários, tanto na Bahia como em Santa Catarina, e às produçóes de sentido das diferentes práticas educativas e culturais construídas no contexto da cultura digital.

\section{Notas}

1 Projeto de pesquisa Gestão e práticas pedagógicas no âmbito do Programa UCA: desafios e estratégias à consolidação de uma política pública para a Educação Básica (2011-2014), financiado pelo Edital MCT/CNPq/CAPES/MEC-SEB no 76/2010 PROUCA.

2 Este levantamento de pesquisas refere-se àquelas realizadas em Escolas que participaram do segundo momento da política federal, o Projeto UCA, em que foram distribuídos laptops para 400 Escolas em todos os Estados da Federação. Nesse sentido, o recorte temporal compreende de 2011 a 2014. Foram encontradas 14 teses e 59 dissertaçóes com pesquisas sobre o Projeto UCA realizadas neste grupo de Escolas. 


\section{REFERÊNCIAS}

ALONSO, Cristina (Coord). Las TIC en Catalunya. Cuadernos de Pedagogia, Catalunya, n. 418, p. 40-43, 2011.

ARAUJO. Maristela. Móbeis, sentidos e redes de saberes: o professor e sua relação com a autoria na Cibercultura. 2014. 254 p. Tese (Doutorado em Educação) Universidade Federal da Bahia, Salvador, BA, 2014.

BRASIL. PRESIDÊNCIA DA REPÚBLICA. Lei no 12.249, de 11 de junho de 2010. Cria o Programa Um Computador por Aluno - PROUCA e institui o Regime Especial de Aquisição de Computadores para Uso Educacional - RECOMPE. Brasília, DF, 2010.

BUCKINGHAM, David. Youht, identity and digital media. Cambridge: The MIT Press, 2008.

CORDEIRO. Salete. Tecnologias digitais móveis no cotidiano escolar: espaços/tempos de aprender. 2014. 315 p. Tese (Doutorado em Educação) - Universidade Federal da Bahia, Salvador, BA, 2014. Tese.

DURAND, Marc; SAURY, Jacques; VEYRUNES, Phillippe. Relaçôes fecundas entre pesquisa e formação: elementos para um programa. Cadernos de Pesquisa, São Paulo, v. 35, n. 125, p. 37-62, maio/ago. 2005.

FARIA, Andréia Borges de. Interaçōes entre professores e estudantes em situaçôes de ensino-aprendizagem mediadas por NTICE: retratos do Projeto UCA no Distrito Federal (DF). 2012.97 p. Dissertação (Mestrado em Educação) - Universidade de Brasília, Brasília, DF, 2012.

FRANÇA, Célia da Conceição de Assis. Inclusão digital na Educação Básica Brasileira - Projeto UCA no estado do Pará: um estudo de caso. 2014.154 p. Dissertação (Mestrado em Educaçáo) - Universidade do Estado de Santa Catarina, Florianópolis, SC, 2014.

GEE, James Paul; HAYES, Elisabeth. Language and learning in the digital age. London: Routledge, 2011.

JENKINS, Henry. Confronting the challenges of participatory culture: media education for the 21st century. Illinois: The MacArthur Foundation, 2006.

KRETZER, Suleica F. B. A prática educativa em um processo de incorporação das tecnologias móveis na Escola. 2013. 134 p. Dissertação (Mestrado em Educação) Universidade Federal de Santa Catarina, Florianópolis, SC, 2013. 
LANKSHEAR, Colin; KNOBEL, Michele. Researching new literacies. E learning, v. 4, n. 3, p. 224-240, 2007.

LANKSHEAR, Colin; KNOBEL, Michele. Front matter and introduction to a new literacies reader: educational perspectives. New York: Peter Lang, 2013. Disponível em:

$<$ http://everydayliteracies.net/files/NewLiteraciesReader_Front_Matter_and_Introd uction.pdf>. Acesso em> 20 dez. 2014.

LONGAREZI, Andrea; SILVA, Jorge. Interface entre pesquisa e formação de professores: delimitando o conceito de pesquisa-formação. In: CONGRESSO NACIONAL DE EDUCAÇÃO, 8., 2008, Curitiba. Anais... Curitiba: PUC/PR, 2008 .

MARTÍN-BARBERO, Jesus; REY, German. Os exercícios do ver: hegemonia audiovisual e ficção televisa. 2. ed. São Paulo: Editora do Senac, 2004.

MIRANDA, Lyana T. Multissensorialidades e aprendizagens: uma perspectiva ecológica sobre os usos das tecnologias móveis pelas crianças na Escola. 2013. 123 p. Dissertação (Mestrado em Educação) - Universidade Federal de Santa Catarina, Florianópolis, SC, 2013.

MOSCOVICI, Serge. Representações Sociais: investigaçôes em psicologia social. 5. ed. Petrópolis, RJ: Vozes, 2009.

NEIRA, Laura. A rede como espaço de encontro: ressignificando o trabalho colaborativo na Escola. Dissertação (Mestrado em Educação) - Universidade Federal de Santa Catarina, Florianópolis, SC, 2014.

PINTO, Dayler Antonio Neves. Análise dos problemas e soluçôes do sistema operacional metasys nos laptops do PROUCA no Colégio de Aplicação da Universidade Federal de Sergipe. 2012. 112 p. Dissertação (Mestrado em Educação) Universidade Tiradentes, Aracajú, SE, 2012.

PIOVANI, Veronica Gabriela Silva. Escola, tecnologia e sociabilidade na educação fisica: intercâmbios pedagógico-culturais no âmbito do plano CEIBAL e do PROUCA. 2012. 214 p. Dissertação (Mestrado em Educação Física) - Universidade Federal de Santa Catarina, Florianópolis, SC, 2012.

QUARTIERO, Elisa Maria; BONILLA, Maria Helena Silveira; FANTIN, Monica. Políticas para la inclusión de las TIC en las escuelas públicas brasileñas: contexto y programas. Campus Virtuales, v. 1, p. 115-129, 2012. Disponível em: $<$ http://issuu.com/revistacampusvirtuales/docs/revista_campusvirtuales_01/21>. Acesso em: 20 nov. 2013. 
QUARTIERO, Elisa Maria; FANTIN, Monica; BONILLA, Maria Helena. Relatório de pesquisa. Florianópolis, SC: CNPq, 2014.

QUARTIERO, Elisa Maria; FANTIN, Monica. Education-Research in Schools: places and authorships in question. Research on Education and Media, Lecce, v. 6, n. 2, p. 35-45, dec. 2014.

RIGONI, Dirce Meri de Rossi Garcia Rafaelli. Laptop Educacional: mecanismos sociocognitivos nos contextos de aprendizagem. 2012. 127 p. Dissertação (Mestrado em Educação) - Universidade de Caxias do Sul, Caxias do Sul, RS, 2012.

RIVOLTELLA, Pier Cesare. Formar a competência midiática: novas formas de consumo e perspectivas educativas. Comunicar, Huelva, n. 25, 2005.

RIVOLTELLA, Pier Cesare. Fare didattica con gli EAS: episodi di Apprendimento Situati. Brescia: La Scuola, 2013.

SARIAN, Maristela Cury. A injunção ao novo e a repetição do velho: um olhar discursivo ao programa um computador por aluno (PROUCA). 2013. 228 p. Tese (Doutorado em Linguística) - Universidade Estadual de Campinas, Campinas, SP, 2013.

SAMPAIO, Fábio; ELIA, Marcos. Projeto Um Computador por Aluno: pesquisas e perspectivas. Rio de Janeiro: NCE, 2012. Disponível em: $<$ http://www.nce.ufrj.br/ginape/livro-prouca/LivroPROUCA.pdf>. Acesso em: 7 nov. 2014.

SCHNEIDER, Fernanda Chagas. Cidade um computador por aluno - UCA Total: uma totalidade inclusiva em discussão. 2012. 231 p. Dissertação (Mestrado em Educação) - Universidade Federal do Rio Grande do Sul, Porto Alegre, RS, 2012.

SANCHO, Juana; ALONSO, Cristina (Org.) La fugacidad de las politicas y la inercia de las prácticas: la educación y las tecnologias de la información y la comunicación. Barcelona: Octaedro, 2012.

SILVA, Adriana Carvalho da. Travessia reflexiva do silêncioldiálogo interior: a construção do professor no contexto da cibercultura. 2012. 191 p. Dissertação (Mestrado em Educação Matemática e Tecnológica) - Universidade Federal de Pernambuco, Pernambuco, 2012.

SILVA. Maria Léa. A inclusão digital nas politicas públicas de inserção das Tecnologias de Informação e Comunicação na Educação: o discurso e a prática dos cursos de formação de professores. 2014. 132 p. Dissertação (Mestrado em Educação) Universidade Federal da Bahia, Salvador, BA, 2014. 
SILVA, Cristiane Oliveira da; SUSIN, Loredana. Aprendizagens e vivências virtuais: uma análise sobre o Projeto UCA em aulas de Ciências. In: SEMINÁRIO DE PESQUISA EM EDUCAÇÃO DA REGIÃO SUL, 9., 2012, Caxias do Sul. Anais... Caxias do Sul, RS: ANPEdSul, 2012.

SOUZA, Marco Antonio. A interação dos estudantes em um ambiente informatizado de aprendizagem matemática: uma experiência dentro do Projeto Um Computador por Aluno - UCA. 2013. 241 p. Dissertação (Mestrado em Educação Matemática) - Universidade Federal de Ouro Preto, Ouro Preto, MG, 2013.

TEIXEIRA, Adriana Gouvêa Dutra. Difusão tecnológica no ensino de línguas: o uso de computadores portáteis nas aulas de Língua Portuguesa sob a ótica da complexidade. 2012. 207 p. Tese (Doutorado em Estudos Linguísticos) Universidade Federal de Minas Gerais, Belo Horizonte, MG, 2012.

TUFTE, Birget; CHRISTENSEN, Olaf. Mídia-educação entre a teoria e a prática. Perspectiva, Florianópolis, SC, v. 27, n. 1, p. 97-118, jan./jun. 2009.

UNESCO. Padröes de competência em TIC para professores: diretrizes de implementação. Brasília: UNESCO, 2008.

VALLE, Lucia Helena Cavalcanti das Neves. Um Computador por Aluno: trajetórias da pesquisa e do pensamento crítico discente na escola. 2011. 127 p. Dissertação (Mestrado em Educação Matemática e Tecnológica) - Universidade Federal de Pernambuco, Recife, 2011.

WARSCHAUER, Martin. Laptops and literacy: learning in the wirelless classroom. New York: Teachers College Press, 2006.

XAVIER. Luiz Guilherme de Souza. O Programa Um Computador por Aluno PROUCA e o ensino de Geografia. 2011. 228 p. Dissertação (Mestrado em Geografia) -Universidade do Estado do Rio de Janeiro, Rio de Janeiro, 2011.

ZANATA, Sérgio. Gestão e Inovação Educacional: as tecnologias móveis no espaço da escola. 2013. 159 p. Dissertação (Mestrado em Educação) - Universidade do Estado de Santa Catarina, Florianópolis, SC, 2013. 


\section{Educational and cultural prac- tices of students and their per- ceptions about the mobile tech- nologies at school}

\begin{abstract}
This article presents an inter-institutional study undertaken in different sociocultural contexts about the Project One computer per student - Projeto Um Computador por Aluno (UCA) -reviewing the focus of the pedagogical practices that goal to make reflections on the educational and cultural practices of students and their perceptions of the project. With a theoretical methodological approach based on media-educational research, the article discusses a multiple case study conducted at four public schools that involved observations of daily school activities, research-education, didactic intervention and focus groups with students from different classes of elementary school. To contextualize the discussion, the article begins with a survey of different studies of the UCA project undertaken from 2011-2014. It then presents the methodology used in the study and a discussion of the specificities of the cultural practices and perceptions of students about the project. Finally, the article presents some considerations that demonstrate that the wealth and diversity of practices present in a single project can also be understood as a polyphony of voices of students, teachers and researchers, as possible interpretations that shape the study in a space of alterity and immersion in the digital culture.
\end{abstract}

Keywords: UCA Project. School culture. Digital inclusion.

\section{Prácticas educativas y cultura- les de estudiantes y sus per- cepciones acerca de las tecno- logías móviles en la escuela}

\section{Resumen}

Situado en una investigación interinstitucional desarrollada en diferentes contextos socioculturales del proyecto Una Computadora por Alumno - Projeto Um Computador por Aluno (UCA) -, el artículo presenta un recorte de las prácticas pedagógicas con el fin de reflexionar sobre las prácticas educativas y culturales de los estudiantes y sus percepciones sobre el proyecto. A partir del abordaje teórico y metodológico basado en la investigación media-educativa, se discute un estudio de casos múltiples en cuatro escuelas públicas lo cual implicó observaciones de la vida escolar cotidiana, la formación en investigación, la intervención didáctica y grupos focales con estudiantes de diferentes clases de la escuela primaria. Para contextualizar la discusión, el texto realiza un levantamiento de las diferentes investigaciones realizadas que tenían como objeto el Proyecto UCA desarrolladas entre 2011 y 2014. A continuación, presenta la opción metodológica de la investigación y el debate sobre los aspectos específicos de las prácticas culturales y las percepciones de los estudiantes sobre el Proyecto. Finalmente, se presentan algunas consideraciones que muestran que la riqueza y la diversidad de estas prácticas en el mismo proyecto también se pueden entender como una polifonía de voces de los estudiantes, profesores e investigadores como posibles interpretaciones que componen esta investigación como un espacio de la alteridad y de inmersión en la cultura digital.

Palabras claves: Proyecto UCA. Cultura Escolar. Inclusión Digital. 


\section{Monica Fantin}

E-mail: monica.fantin@ufsc.br

\section{Elisa Maria Quartiero}

E-mail: elisa.quartiero@gmail.br

Recebido em: 12/01/2015

Aprovado em: 22/03/2015 